\title{
Enhanced activity of carbosilane dendrimers against HIV when combined with reverse transcriptase inhibitor drugs: searching for more potent microbicides
}

\author{
This article was published in the following Dove Press journal: \\ International Journal of Nanomedicine \\ 29 July 2014 \\ Number of times this article has been viewed
}

\author{
Enrique Vacas-Córdoba ${ }^{1-3}$ \\ Marta Galán 3,4 \\ Francisco J de la Mata ${ }^{3,4}$ \\ Rafael Gómez ${ }^{3,4}$ \\ Marjorie Pion ${ }^{1-3}$ \\ M Ángeles Muñoz- \\ Fernández ${ }^{1-3}$ \\ 'Laboratorio InmunoBiología \\ Molecular, Hospital General \\ Universitario Gregorio Marañón, \\ Madrid, Spain; ${ }^{2}$ Instituto de \\ Investigación Sanitaria del \\ Gregorio Marañón, Madrid, Spain; \\ ${ }^{3}$ Networking Research Center on \\ Bioengineering, Biomaterials and \\ Nanomedicine, (CIBER-BBN), Madrid, \\ Spain; ${ }^{4}$ Dendrimers for Biomedical \\ Applications Group (BiolnDen), \\ University of Alcalá, Madrid, Spain
}

Correspondence: M Ángeles

Muñoz-Fernández

Laboratorio InmunoBiología Molecular,

Hospital General Universitario Gregorio

Marañón, CIBER BBN, C/Dr Esquerdo 46,

28007 Madrid, Spain

Tel +9l 5868565

Fax +915868018

Email mmunoz.hgugm@gmail.com/

mmunoz.hgugm@salud.madrid.org

\begin{abstract}
Self-administered topical microbicides or oral preexposure prophylaxis could be very helpful tools for all risk groups to decrease the human immunodeficiency virus (HIV)-1 infection rates. Up until now, antiretrovirals (ARVs) have been the most advanced microbicide candidates. Nevertheless, the majority of clinical trials has failed in HIV-1 patients. Nanotechnology offers suitable approaches to develop novel antiviral agents. Thereby, new nanosystems, such as carbosilane dendrimers, have been shown to be safe and effective compounds against HIV with great potential as topical microbicides. In addition, because most of the attempts to develop effective topical microbicides were unsuccessful, combinatorial strategies could be a valid approach when designing new microbicides. We evaluated various combinations of anionic carbosilane dendrimers with sulfated (G3-S16) and naphthyl sulfonated (G2-NF16) ended groups with different ARVs against HIV-1 infection. The G3-S16 and G2-NF16 dendrimers showed a synergistic or additive activity profile with zidovudine, efavirenz, and tenofovir in the majority of the combinations tested against the X4 and R5 tropic HIV-1 in cell lines, as well as in human primary cells. Therefore, the combination of ARVs and polyanionic carbosilane dendrimers enhances the antiviral potency of the individual compounds, and our findings support further clinical research on combinational approaches as potential microbicides to block the sexual transmission of HIV-1.
\end{abstract}

Keywords: microbicides, HIV, carbosilane dendrimer, antiretroviral, synergy

\section{Introduction}

Great international efforts have been made to fight against the acquired immune deficiency syndrome (AIDS) epidemic. Although the number of newly infected human immunodeficiency virus (HIV)-1 patients has significantly decreased, according to the latest data from 2012, there were still 2.3 million newly infected HIV-1 patients worldwide, most of whom contracted the virus during sexual intercourse. ${ }^{1}$ In addition, highly active antiretroviral therapy delays disease progression and significantly decreases the mortality rate in HIV-infected patients. ${ }^{2}$ However, this therapy neither cures the HIV infection nor eliminates the virus. Therefore, new strategies or improvements of the existing ones are necessary to prevent new transmissions. Self-administered topical microbicides or oral preexposure prophylaxis may be helpful tools to decrease the HIV infection rate. ${ }^{3,4}$

Several antiretrovirals (ARVs), such as the non-nucleoside reverse transcriptase inhibitors (UC781, ${ }^{5}$ dapivirine,${ }^{6}$ or rilpivirine),${ }^{7}$ fusion inhibitors such as griffithsin, sifuvirtide, C52L, and cyanovirin, ${ }^{8,9} \mathrm{C}-\mathrm{C}$ chemokine receptor type 5 (CCR5) coreceptor inhibitors, including CMPD167, PSC-RANTES, and maraviroc ${ }^{10,11}$ or 
protease inhibitors, such as saquinavir, ${ }^{12}$ which block different steps of HIV-1 life cycle, have been used as topical microbicides. ${ }^{13,14}$

Although tenofovir (TFV), a nucleoside reverse transcriptase inhibitor formulated as $1 \%$ gel, showed a reduction of HIV-1 acquisition by an estimated $39 \%$ in the Centre for the AIDS Programme of Research in South Africa (CAPRISA) 004 clinical trial in South African women, ${ }^{15}$ the majority of topical microbicides has failed due to a lack of efficacy or adherence. ${ }^{16,17}$ It implies that additional efforts are needed to develop reliable and effective microbicide strategies.

As it has already been shown, a combination of at least two different families of ARVs is more effective at treating HIV-1 infection than monotherapy. ${ }^{18}$ Therefore, the combinatorial approach should be taken into consideration when designing future microbicide studies. Some novel studies have examined the efficacy of ARV combinations as microbicides. ${ }^{19,20}$

Currently, nanotechnology provides new and suitable approaches to obtain novel, potent, and safer antiviral agents, such as dendrimers. ${ }^{21-24}$ Dendrimers, unlike conventional linear polymers, are characterized by a three-dimensional, hyperbranched multivalent nanostructure with low polydispersity. Interestingly, dendrimers can be engineered by manipulating their structures or the composition and number of their surface functional groups to lead out different biomedical applications. In this way, polyanionic carbosilane dendrimers have shown high anti-HIV activity in vitro and exhibit potential as microbicide candidates. ${ }^{24}$ Moreover, we have already shown that combination of maraviroc and the polyanionic carbosilane dendrimers G3-S16 and G2-NF16 increased their antiviral potency, both additively and synergistically, against CCR5-tropic HIV; the main viral strain involved in primary infection during sexual transmission, and dual tropic HIV-1 isolates. ${ }^{25}$

In this work, we studied the combinatorial activity profile of these polyanionic carbosilane dendrimers (G3-S16 and G2-NF16; Figure 1) in combination with other ARVs, such as zidovudine (AZT), efavirenz (EFV), and TFV,
A

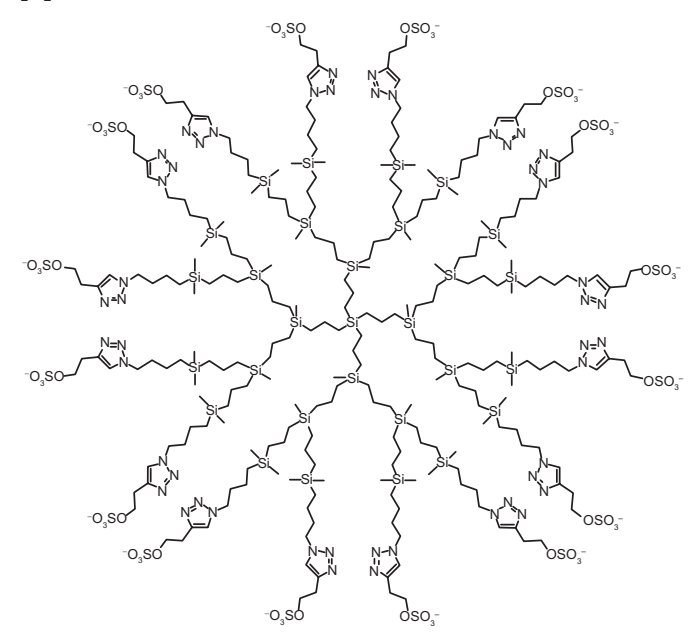

C
B

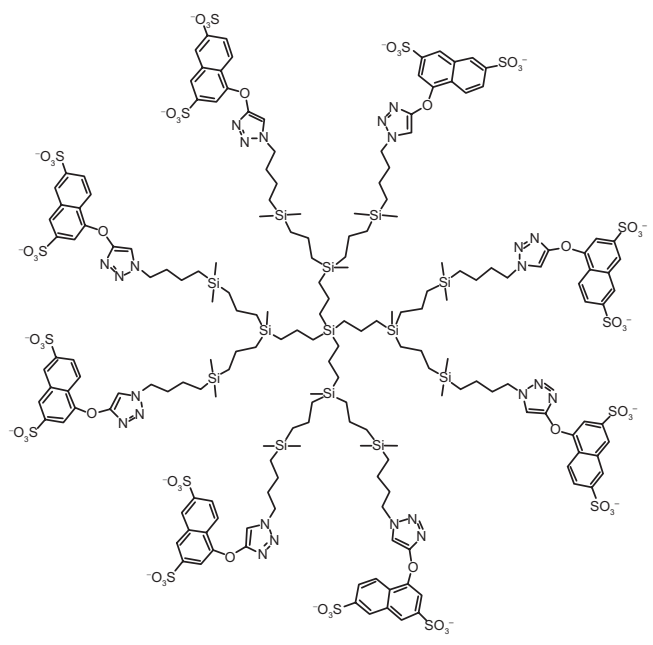

E

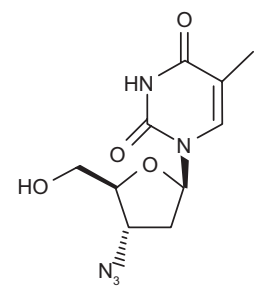

D

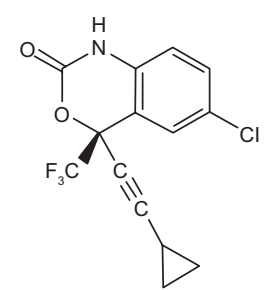

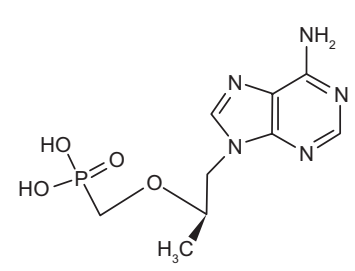

Figure I Structure of polyanionic carbosilane dendrimers and ARV drugs.

Notes: (A) Third-generation G3-SI6, with 16 sulfated end groups. $\mathrm{C}_{256} \mathrm{H}_{508} \mathrm{~N}_{48} \mathrm{Na}_{16} \mathrm{O}_{64} \mathrm{~S}_{16} \mathrm{Si}_{29} ;$ mw, 6,978.4I g/mol. (B) Second-generation G2-NFI6, with I6 naphthyl sulfonated end groups. $\mathrm{C}_{184} \mathrm{H}_{244} \mathrm{~N}_{24} \mathrm{Na}_{16} \mathrm{O}_{56} \mathrm{~S}_{16} \mathrm{Si}_{13} ; \mathrm{mw}, 4,934.02 \mathrm{~g} / \mathrm{mol}$. Dendrimers, with a $>95 \%$ purity as tested by high-performance liquid chromatography, were prepared according to the methods reported by the Dendrimers for Biomedical Applications Group of University of Alcalá (Madrid, Spain). (C) Zidovudine (AZT), $\mathrm{C}_{10} \mathrm{H}_{13} \mathrm{~N}_{5} \mathrm{O}_{4}$; mw, $267.242 \mathrm{~g} / \mathrm{mol}$. (D) EFV, $\mathrm{C}_{14} \mathrm{H}_{9} \mathrm{~N}_{1} \mathrm{O}_{2} \mathrm{Cl}_{1} \mathrm{~F}_{3}$; mw, $315.675 \mathrm{~g} / \mathrm{mol}$. (E) TFV, $\mathrm{C}_{9} \mathrm{H}_{14} \mathrm{~N}_{5} \mathrm{O}_{4} \mathrm{P} ; \mathrm{mw}, 287.213 \mathrm{~g} / \mathrm{mol}$.

Abbreviations: $\mathrm{mw}$, molecular weight; $\mathrm{AZT}$, zidovudine; $\mathrm{EFV}$, efavirenz; TFV, tenofovir. 
to evaluate their potential as anti-HIV-1 microbicides. The additional value of these combinations is that dendrimers or ARVs have the potential to block HIV-1 infection at different stages of the HIV-1 life cycle. Presumably, dendrimers act during viral entry; whereas, these ARVs have been shown to play a decisive role in reverse transcriptase inhibition. Both types of chemical compounds act during the first steps of HIV-1 replication in the aim of preventing viral integration.

\section{Materials and methods Cells and cell culture}

The TZM-bl cell line (National Institutes of Health [NIH] AIDS Research and Reference Reagent Program, Germantown, MD, USA) was derived from the HeLa cell line and contains integrated copies of the luciferase and $\beta$-galactosidase genes under the control of the HIV-1 promoter. ${ }^{26}$ The TZM-bl cells were cultured as described. ${ }^{25}$ Peripheral blood mononuclear cells (PBMCs) were isolated using a standard Ficoll gradient from buffy coats (Rafer, Spain) and were cultured as previously described. ${ }^{27}$

\section{Viruses}

C-X-C chemokine receptor type 4 (CXCR4)-tropic X4-HIV-1 ${ }_{\mathrm{NL} 4-3}$ and CCR5-tropic R5-HIV-1 ${ }_{\mathrm{NL}(\mathrm{AD} 8)}$ laboratory strains were obtained by transient transfection of the pNL4-3 and pNL(AD8) plasmids (NIH AIDS Research and Reference Reagent Program) into 293-T cells (American Type Culture Collection [ATCC], Manassas, VA, USA). The viral tropism is determined by the surface coreceptor that is used by the HIV-1 at the entry step into the cluster of differentiation (CD) 4+ target cells. We can distinguish between CXCR4 (X4), CCR5 (R5), or dual (X4/R5)-tropic HIV-1 strains, depending on whether they use the CXCR4, CCR5 coreceptors, or both, respectively. The primary clinical R5-tropic HIV-1 isolate X-1936 (clade C) was provided by Dr L Pérez (Instituto de Salud Carlos III, Madrid, Spain). Viral stocks were clarified by centrifugation prior to evaluating the viral titer using the HIVp24 ${ }^{\text {gag }}$ enzyme-linked immunosorbent assay (ELISA) kit (INNOTEST ${ }^{\circledR}$ HIV-Antigen mAb; Innogenetics NV, Ghent, Belgium).

\section{Reagents}

The anionic carbosilane dendrimers G3-S16 and G2-NF16, ${ }^{24}$ with a $>95 \%$ purity as tested by high-performance liquid chromatography, were prepared according to the methods reported by the Dendrimers for Biomedical Applications
Group of University of Alcalá (Madrid, Spain). ${ }^{28}$ The dendrimers were dissolved in distilled water at a final concentration of $1 \mathrm{mM}(6.978 \mathrm{mg} / \mathrm{mL}$ for G3-S16; $4.934 \mathrm{mg} /$ $\mathrm{mL}$ for $\mathrm{G} 2-\mathrm{NF} 16)$. Dilutions to the $\mu \mathrm{M}$ range were made using phosphate buffered saline (Lonza, Walkersville, MD, USA). The ARVs zidovudine (AZT; ViiV Healthcare, Middlesex, UK), efavirenz (EFV; Bristol-Myers Squibb, New York, NY, USA), and tenofovir disoproxil fumarate (TFV; Gilead Science, Foster City, CA, USA) were obtained in tablet form. The tablets were ground into a powder, freshly dissolved in dimethyl sulfoxide, and filter sterilized.

\section{Antiviral assays and combination experiments}

The methodology used for single and combined drug antiviral activity assays has been previously described in detail. ${ }^{29}$ The TZM-bl or PBMC cells were treated with different concentrations of the tested compounds or their combinations for 1 hour before HIV-1-infection with $20 \mathrm{ng} / 1 \times 10^{6}$ cells of the X4-HIV-1 ${ }_{\mathrm{NL} 4-3}$ or R5-HIV-1 ${ }_{\mathrm{NL}(\mathrm{AD} 8)}$ isolates. Three days after infection, the HIV-1 replication was determined by the quantification of luciferase expression (Promega Corporation, Madison, WI, USA) or by analysis of the $\mathrm{p} 24^{\mathrm{gag}}$ antigen using an ELISA. The $50 \%, 75 \%$, and $90 \%$ effective concentrations ( $\mathrm{EC}_{50}, \mathrm{EC}_{75}$, and $\mathrm{EC}_{90}$, respectively) were determined, and synergism analysis was performed using the CalcuSyn software (Biosoft, Cambridge, UK), based on the median effect principle. ${ }^{30}$ The combination index (CI) of each drug combination was plotted as a function of the fractional inhibition by computer simulation; the fractional inhibition values ranged from $0.10-0.95$. CI values between $0.1-0.9$ indicate a synergistic effect; whereas, values between 0.9-1.1 represent an additive effect, and $>1.1$ represents antagonism. Each experiment was performed in triplicate.

\section{Cell viability assays}

Cell viability was determined using an (3-(4,5-dimethylthiazol2-yl)-5-(3-carboxymethoxyphenyl)-2-(4-sulfophenyl)-2Htetrazolium) (MTS) (Promega Corporation) assay, according to the manufacturer's instructions. Each experiment was performed in triplicate.

\section{Statistical analysis}

Statistical analysis was performed using the Kruskal-Wallis nonparametric test. The significance level was set as $P=0.05$. The GraphPad Prism V5.0 software (GraphPad Software, Inc., La Jolla, CA, USA) was used. 


\section{Results}

Increased efficiency of dendrimer/antiviral drug combination in primary human cells

Combinations of G3-S16 and G2-NF16 with AZT, EFV, and TFV were tested against X4- and R5- tropic HIV-1 in PBMCs, which are the main targets of HIV-1 infection in vivo. For these experiments, equipotent (1:1) ratio combinations were tested. Previously, we performed a toxicity assay to evaluate the biocompatibility of these combinations in PBMCs. Neither the combinations nor the individual drug concentrations were toxic for PBMCs after 24 hours of exposure (Table 1).

To analyze the antiviral activity of each individual drug or its combinations, we determined the $\mathrm{EC}_{50}$ of each antiviral drug alone, followed by the two-drug combinations of dendrimers + AZT, dendrimers + EFV, and dendrimers + TFV (Table 2). As shown, despite the variability among the different donors in the single experiments, the majority of the evaluated combinations achieved a reduction in the $\mathrm{EC}_{50}$ values when the dendrimers were combined with the ARVs, as compared to their individual drug $\mathrm{EC}_{50}$ values, against both the X4-HIV-1 ${ }_{\mathrm{NL} 4.3}$ and R5-HIV-1 ${ }_{\mathrm{NL}(\mathrm{AD} 8)}$ isolates. For example, G3-S16 and AZT alone inhibited X4-HIV-1 ${ }_{\text {NL4.3 }}$ with an average $\mathrm{EC}_{50}$ of $0.632 \mu \mathrm{M}$ and $68 \mathrm{nM}$, respectively (Table 2). The combination G3-S16 and AZT inhibited X4-HIV-1 ${ }_{\text {NL4.3 }}$ with an average $\mathrm{EC}_{50}$ of $22 \mathrm{nM}$, which corresponded to reductions of approximately 28.72- and 3.09-fold, compared to their individual $\mathrm{EC}_{50}$ values. The same effect was observed when the drugs were tested against R5-HIV-1 $1_{\mathrm{NL}(\mathrm{AD} 8)}$ infection. G3-S16 inhibited R5-HIV-1 $1_{\mathrm{NL}(\mathrm{AD} 8)}$ with an average $\mathrm{EC}_{50}$ of $0.856 \mu \mathrm{M}$, and 40.76- and 1.81-fold reductions were observed when G3-S16 was combined with AZT, compared to their individual $\mathrm{EC}_{50}$ values. A reduction of 57.06- and 16.8-fold, compared to their individual $\mathrm{EC}_{50}$ values, was also observed for the G3-S16 + EFV combination (Table 2).

The same effect was also demonstrated with G2-NF16. Reductions of 4.46- and 174.6-fold were found for the G2-NF16 + AZT combination against X4-HIV-1 ${ }_{\mathrm{NL} 4.3}$ and R5-HIV-1 ${ }_{\mathrm{NL}(\mathrm{AD} 8)}$, when compared to the individual G2-NF16 $\mathrm{EC}_{50}$ (Table 2). High reductions in $\mathrm{EC}_{50}$ values were also found when G2-NF16 was combined with EFV against both $\mathrm{X} 4-\mathrm{HIV}-1_{\mathrm{NL} 4.3}$ and R5-HIV-1 ${ }_{\mathrm{NL}(\mathrm{AD} 8)}$ isolates.

Moreover, the combinations of G3-S16 and G2-NF16 with each ARV in the activated PBMCs from different donors resulted in a more efficient inhibitory profile against HIV-1 replication for most of the concentrations tested, measured by using p24 $4^{\mathrm{gag}}$ HIV ELISA (Table 2).

\section{Enhanced profile of dendrimers and ARV combinations in primary human cells against HIV-I replication}

After having demonstrated an enhanced antiviral activity against HIV-1 when the dendrimers were combined with ARVs,

Table I Viability of dendrimer-ARV combinations in PBMCs after 24 hours of treatment

\begin{tabular}{|c|c|c|c|c|c|c|c|c|}
\hline & Concentration $[\mu \mathrm{M}]$ & & G3-S16 & & & G2-NFI 6 & & \\
\hline A & & 0 & 0.01 & 0.1 & 0.5 & 0.01 & 0.1 & 0.5 \\
\hline \multirow[t]{4}{*}{ AZT } & 0 & $100 \pm 0.00$ & $100.50 \pm 5.66$ & $97.91 \pm 18.94$ & $91.04 \pm 1.13$ & $109.76 \pm 0.17$ & $96.27 \pm 4.32$ & $98.07 \pm|6.3|$ \\
\hline & 0.01 & $97.83 \pm 4.64$ & $104.61 \pm 17.57$ & $112.35 \pm 12.55$ & $87.89 \pm 9.92$ & $90.22 \pm 0.65$ & $102.98 \pm 13.66$ & $95.91 \pm 10.52$ \\
\hline & 0.1 & $107.49 \pm 4.58$ & $94.23 \pm 19.554$ & $|20.74 \pm| 4.2$ & $97.01 \pm|0.4|$ & $105.26 \pm 6.54$ & $102.78 \pm 4.93$ & $100.76 \pm 1.48$ \\
\hline & 0.5 & $113.56 \pm 13.69$ & || $7.63 \pm 8.3 \mid$ & $116.74 \pm 33.69$ & $103.06 \pm 8.25$ & $110.64 \pm 18.86$ & $111.24 \pm 3.8$ & $102.17 \pm 5.16$ \\
\hline B & & 0 & 0.01 & 0.1 & I & 0.01 & 0.1 & I \\
\hline \multirow[t]{4}{*}{ EFV } & 0 & $100 \pm 0.00$ & $106.09 \pm 7.4$ & $116.08 \pm 13.34$ & $102.49 \pm 14.48$ & $111.99 \pm 11.53$ & $104.49 \pm 0.97$ & $110.36 \pm 11.58$ \\
\hline & 0.01 & $101.87 \pm 11.58$ & $98.94 \pm 18.74$ & $95.89 \pm 8.06$ & $85.94 \pm 7.89$ & $94.94 \pm 10.02$ & $96.13 \pm 2.42$ & $|02.94 \pm 1.4|$ \\
\hline & 0.1 & $89.03 \pm 1.5$ & $94.98 \pm 5.08$ & $92.38 \pm 0.2$ & $88.01 \pm 2.99$ & $100.85 \pm 8.39$ & $93.39 \pm 2.37$ & $93.66 \pm 19.34$ \\
\hline & I & $102.43 \pm 25.53$ & $97.68 \pm 23.01$ & $99.44 \pm 21.03$ & $96.96 \pm 9.56$ & $110.89 \pm 5.17$ & $107.75 \pm 3.03$ & || $0.28 \pm|.2|$ \\
\hline C & & 0 & 0.01 & 0.1 & 0.5 & 0.01 & 0.1 & 0.5 \\
\hline \multirow[t]{4}{*}{ TFV } & 0 & $100 \pm 0.00$ & $105.63 \pm 18.98$ & $|03.75 \pm 23.3|$ & $105.49 \pm 27.14$ & $96.82 \pm 27.71$ & $101.01 \pm 32.24$ & $109.84 \pm 8.39$ \\
\hline & 0.01 & $104.93 \pm \mid 1.24$ & $102.67 \pm 15.94$ & $91.76 \pm 17.87$ & $93.97 \pm 32.21$ & $103.17 \pm 22.55$ & $95.59 \pm 31.58$ & $103.1| \pm 6.0|$ \\
\hline & 0.1 & $103.64 \pm 8.72$ & $96.33 \pm 11.38$ & $90.24 \pm 26.48$ & $|0| .95 \pm|| .3 \mid$ & $97.76 \pm 13.46$ & $101.21 \pm 17.29$ & $93.53 \pm 7.99$ \\
\hline & 0.5 & $95.77 \pm 12.88$ & $89.56 \pm 11.84$ & $101.21 \pm 16.21$ & $95.91 \pm 23.15$ & $102.86 \pm 17.87$ & $101.05 \pm 17.94$ & $97.59 \pm 3.55$ \\
\hline
\end{tabular}

Notes: MTS assay was performed to evaluate the toxicity of drug combinations. Viability of PBMCs was evaluated for carbosilane dendrimers/AZT combination (A), for carbosilane dendrimers/EFV combination (B), or for carbosilane dendrimers/TFV combination (C). The $80 \%$ of viability was set as the limit of toxicity for all conditions. Each experiment was performed in triplicate. Data are represented as mean \pm SD of two independent experiments.

Abbreviations: ARV, antiretroviral; PBMC, peripheral blood mononuclear cell; AZT, zidovudine; EFV, efavirenz; TFV, tenofovir; MTS, 3-(4,5-dimethylthiazol-2-yl)-5(3-carboxymethoxyphenyl)-2-(4-sulfophenyl)-2H-tetrazolium inner salt; SD, standard deviation. 
Table $2 \mathrm{EC}_{50}$ values $(\mu \mathrm{M} \pm \mathrm{SD}$ ) of G3-SI6, G2-NFI6, AZT, EFV, TFV drugs alone and in combination at equipotent (I:I) ratio against X4-HIV-I ${ }_{\text {LL4.3 }}$ and R5-HIV-I ${ }_{\text {NL(AD8) }}$ in primary PBMCs

\begin{tabular}{|c|c|c|c|c|c|c|}
\hline & \multicolumn{4}{|c|}{$\mathrm{EC}_{50}$ individual drug ${ }^{\Lambda}$} & \multicolumn{2}{|c|}{$\mathrm{EC}_{50}$ combination $^{\circ}$} \\
\hline & Dendrimer & & Inhibitor & & G3-SI 6/RTI & G2-NF I 6/RTI \\
\hline \multirow[t]{3}{*}{ X4 HIV-I ${ }_{\mathrm{NL} 4.3}$} & G3-SI6 & $0.632 \pm 0.626$ & AZT & $0.068 \pm 0.045$ & $0.022 \pm 0.024^{*}$ & $0.030 \pm 0.029 *$ \\
\hline & G2-NFI6 & $0.134 \pm 0.050$ & $\mathrm{EFV}$ & $0.058 \pm 0.077$ & $0.013 \pm 0.009 *$ & $0.016 \pm 0.004$ \\
\hline & & & TFV & $0.001 \pm 0.002$ & $0.003 \pm 0.003$ & $0.00 I \pm 0.00 I^{*}$ \\
\hline \multirow[t]{3}{*}{ R5 HIV-I NL(AD8) } & G3-SI6 & $0.856 \pm 0.757$ & AZT & $0.038 \pm 0.014$ & $0.021 \pm 0.017 *$ & $0.038 \pm 0.029$ \\
\hline & G2-NFI6 & $6.634 \pm 9.090$ & EFV & $0.252 \pm 0.403$ & $0.015 \pm 0.001$ & $0.024 \pm 0.007 *$ \\
\hline & & & TFV & $0.006 \pm 0.002$ & $0.003 \pm 0.002 *$ & $0.00 \mathrm{I} \pm 0.00 \mathrm{I} *$ \\
\hline
\end{tabular}

Notes: ${ }^{\triangle} 50 \%$ effective concentration for HIV-I infection in PBMCs after single drug treatment. ${ }^{\circ} 50 \%$ effective concentration after two-drug combination at equipotent ratio (I:I). Data are represented as mean of three single donors. $* P<0.05$ (nonparametric Kruskal-Wallis statistical analysis), compared to a single drug treatment.

Abbreviations: $\mathrm{EC}_{50}, 50 \%$ effective concentration; SD, standard deviation; AZT, zidovudine; EFV, efavirenz; TFV, tenofovir; PBMCs, peripheral blood mononuclear cells; $\mathrm{RTI}$, reverse transcriptase inhibitor.

the CI was calculated to evaluate the type of dendrimer and ARV interactions (Table 3). The CalcuSyn software, based on the median effect principle, was used. ${ }^{30}$ The CI values between $0.1-0.9$ indicate a synergistic effect; whereas, values between 0.9-1.1 represent an additive effect, and $>1.1$ represents antagonism.
A synergistic profile (CI values between 0.46-0.49) and additive effects were found at the calculated $\mathrm{EC}_{50}$ and $\mathrm{EC}_{75}$ for G3-S16 + AZT against both the X4 and R5-HIV-1 isolates, respectively. An additive effect was observed at the $\mathrm{EC}_{90}$ for X4-HIV-1 ${ }_{\mathrm{NL} 4.3}$, but not against R5-HIV-1 ${ }_{\mathrm{NL}(\mathrm{AD} 8)}$. An additive effect (CI values between 0.92-0.95) and a strong

Table 3 Synergy and $\mathrm{Cl}(\mathrm{Cl} \pm \mathrm{SD})$ calculations for different ARVs (AZT, EFV, or TFV) and G3-SI6 or G2-NFI6 combinations at equipotent (I:I) ratio against X4-HIV-I ${ }_{\mathrm{NL4.3}}$ and R5-HIV-I $\mathrm{NL(AD8)}$ isolates in primary PBMCs

\begin{tabular}{|c|c|c|c|c|}
\hline \multirow[t]{2}{*}{ Combination } & \multirow[t]{2}{*}{ Virus } & \multicolumn{3}{|l|}{$\mathrm{Cl}^{\mathrm{a}, \mathrm{b}}$} \\
\hline & & $E C_{50}$ & $E C_{75}$ & $E C_{90}$ \\
\hline G3-SI6/AZT & X4 HIV-I ${ }_{\mathrm{NL} 4.3}$ & $\begin{array}{l}0.46 \pm 0.39 \\
(+++)\end{array}$ & $\begin{array}{l}0.49 \pm 0.52 \\
(+++)\end{array}$ & $\begin{array}{l}0.96 \pm 1.38 \\
( \pm)\end{array}$ \\
\hline G3-SI6/EFV & X4 HIV-I ${ }_{\mathrm{NL} 4.3}$ & $\begin{array}{l}0.95 \pm 0.37 \\
( \pm)\end{array}$ & $\begin{array}{l}0.93 \pm 0.35 \\
( \pm)\end{array}$ & $\begin{array}{l}0.92 \pm 0.33 \\
( \pm)\end{array}$ \\
\hline G3-SI6/TFV & X4 HIV-I ${ }_{\mathrm{NL} 4.3}$ & $\begin{array}{l}0.73 \pm 0.03 \\
(++)\end{array}$ & $\begin{array}{l}0.78 \pm 0.11 \\
(++)\end{array}$ & $\begin{array}{l}0.83 \pm 0.19 \\
(++)\end{array}$ \\
\hline G2-NFI6/AZT & X4 HIV-I ${ }_{\text {NL4.3 }}$ & $\begin{array}{l}0.63 \pm 0.45 \\
(+++)\end{array}$ & $\begin{array}{l}0.55 \pm 0.29 \\
(+++)\end{array}$ & $\begin{array}{l}0.70 \pm 0.5 \text { I } \\
(++)\end{array}$ \\
\hline G2-NFI6/EFV & X4 HIV-I ${ }_{\text {NL4.3 }}$ & $(-)$ & $\begin{array}{l}0.99 \pm 0.14 \\
( \pm)\end{array}$ & $\begin{array}{l}0.81 \pm 0.41 \\
(++)\end{array}$ \\
\hline G2-NFI6/TFV & X4 HIV-I ${ }_{\text {NL4.3 }}$ & $\begin{array}{l}0.01 \pm 0.01 \\
(+++++)\end{array}$ & $\begin{array}{l}0.01 \pm 0.01 \\
(+++++)\end{array}$ & $\begin{array}{l}0.01 \pm 0.01 \\
(+++++)\end{array}$ \\
\hline G3-SI6/AZT & R5 HIV-I ${ }_{N L(A D 8)}$ & $\begin{array}{l}0.97 \pm 0.62 \\
( \pm)\end{array}$ & $\begin{array}{l}1.10 \pm 1.11 \\
( \pm)\end{array}$ & $(-)$ \\
\hline G3-SI6/EFV & R5 HIV-I ${ }_{N L(A D 8)}$ & $\begin{array}{l}0.45 \pm 0.15 \\
(+++)\end{array}$ & $\begin{array}{l}0.39 \pm 0.22 \\
(+++)\end{array}$ & $\begin{array}{l}0.34 \pm 0.26 \\
(+++)\end{array}$ \\
\hline G3-SI6/TFV & R5 HIV-I ${ }_{N L(A D 8)}$ & $(-)$ & $\begin{array}{l}0.95 \pm 0.48 \\
( \pm)\end{array}$ & $\begin{array}{l}0.5 I \pm 0.18 \\
(+++)\end{array}$ \\
\hline G2-NFI6/AZT & R5 HIV-I ${ }_{\text {NL(AD8) }}$ & $\begin{array}{l}0.84 \pm 0.37 \\
(+)\end{array}$ & $\begin{array}{l}0.45 \pm 0.45 \\
(+++)\end{array}$ & $\begin{array}{l}0.30 \pm 0.38 \\
(+++)\end{array}$ \\
\hline G2-NFI6/EFV & R5 HIV-I ${ }_{\text {NL(AD8) }}$ & $\begin{array}{l}0.91 \pm 0.48 \\
( \pm)\end{array}$ & $\begin{array}{l}0.7 I \pm 0.45 \\
(++)\end{array}$ & $\begin{array}{l}0.59 \pm 0.48 \\
(+++)\end{array}$ \\
\hline G2-NFI6/TFV & R5 HIV-I ${ }_{N L(A D 8)}$ & $\begin{array}{l}0.16 \pm 0.12 \\
(++++)\end{array}$ & $\begin{array}{l}0.22 \pm 0.13 \\
(++++)\end{array}$ & $\begin{array}{l}0.3 \mathrm{I} \pm 0.15 \\
(+++)\end{array}$ \\
\hline $\begin{array}{l}\text { Notes: a }{ }^{\mathrm{Cl}} \text { calcula } \\
\text { level: } \pm \text { indicates a } \\
\text { synergism); } 0.1>C \\
\text { performed in dupli } \\
\text { Abbreviations: } \mathrm{C}\end{array}$ & $\begin{array}{l}\mathrm{d} \mathrm{EC} \mathrm{E}_{90} \text { level. } \mathrm{Cl}< \\
<0.9+(\text { slight syr } \\
\text { ynergism). An eq } \\
\text { ed as the mean of } \\
50 \% \text { effective } \mathrm{cc}\end{array}$ & $\begin{array}{l}0.9<\mathrm{Cl}<\mathrm{l} . \mathrm{I} \\
++ \text { (moderat } \\
V \text { range conce } \\
\text { eriments. } \\
\text { effective conc }\end{array}$ & $\begin{array}{l}\text { ss, and } \mathrm{Cl}>\mathrm{I} . \\
0.7+++(\text { syn } \\
\mu \mathrm{M} \text { and } \mathrm{I} \mu\end{array}$ & $\begin{array}{l}(-) .{ }^{\text {'SSynergy }} \\
+++ \text { (potent } \\
\text { periment was } \\
\text { viation; ARV, }\end{array}$ \\
\hline
\end{tabular}


synergy profile (CI values approximately 0.34-0.45) were found for the G3-S16 + EFV combination against X4 and R5-HIV-1, respectively. Additionally, moderate synergism $(\mathrm{CI}=0.83)$ and strong synergy $(\mathrm{CI}=0.51)$ were observed at the calculated $\mathrm{EC}_{90}$ for the G3-S16 + TFV combination against X4 and R5-HIV-1, respectively. Nonenhanced inhibitory profiles were found at the $\mathrm{EC}_{50}$ concentration against R5-HIV-1 ${ }_{\text {NL(AD8) }}$.

Similarly, synergistic or additive profiles against HIV infection were observed for all of the calculated $\mathrm{EC}_{50}, \mathrm{EC}_{75}$, and $\mathrm{EC}_{90}$ values for the two-drug combinations of G2-NF16 and AZT, EFV, or TFV against both the X4 and R5-HIV-1 isolates, excepted for the G2-NF16 + EFV combination against the X4-HIV-1 at the calculated $\mathrm{EC}_{50}$. It was interesting to note that strong and very strong synergy profiles were observed (CI values between $0.01-0.31$ ) for the G2-NF16 + TFV combination against the $\mathrm{X} 4$ and $\mathrm{R} 5-\mathrm{HIV}-1$ isolates, respectively.

Furthermore, the antiviral activity of the dendrimer/ reverse transcriptase inhibitors drug combinations was evaluated against the human primary subtype C (R5)-HIV-1 isolate, which is the most common HIV-1 subtype worldwide (Table 4). Preliminary results showed that synergistic profiles (CI values between 0.012-0.54) were observed at the calculated $\mathrm{EC}_{90}$ values for all combinations against the subtype C-HIV-1 strain, except for the G3-S16/TFV combination. Summing up, synergistic and additive profiles were observed

Table 4 Synergy and $\mathrm{Cl}$ calculations for different ARVs (AZT, EFV, or TFV) and dendrimers combinations at equipotent (I:I) ratio against clinical subtype C-HIV-I strain in primary PBMCs

\begin{tabular}{|c|c|c|}
\hline \multirow[t]{2}{*}{ Combination } & \multicolumn{2}{|l|}{$\mathrm{Cl}^{\mathrm{a}}$} \\
\hline & $\mathrm{EC}_{75}$ & $E C_{90}$ \\
\hline \multirow[t]{2}{*}{$\overline{\text { G3-SI6/AZT }}$} & 0.431 & 0.387 \\
\hline & $(+++)$ & $(+++)$ \\
\hline \multirow[t]{2}{*}{ G2-NFI6/AZT } & 0.506 & 0.182 \\
\hline & $(+++)$ & $(++++)$ \\
\hline \multirow[t]{2}{*}{ G3-SI6/EFV } & 0.479 & 0.288 \\
\hline & $(+++)$ & $(+++)$ \\
\hline \multirow[t]{2}{*}{ G2-NFI6/EFV } & 1.028 & 0.547 \\
\hline & $( \pm)$ & $(+++)$ \\
\hline \multirow[t]{2}{*}{ G3-SI6/TFV } & 0.001 & $(-)$ \\
\hline & $(+++++)$ & \\
\hline \multirow[t]{2}{*}{ G2-NFI 6/TFV } & $(-)$ & 0.012 \\
\hline & & $(+++++)$ \\
\hline
\end{tabular}

Notes: ${ }^{a} \mathrm{Cl}$ calculated at the $\mathrm{EC}_{75}$ and $\mathrm{EC}_{90}$ level. $\mathrm{Cl}<0.9$ indicates synergism; $0.9<\mathrm{Cl}<\mathrm{I}$.l indicates additive effects and $\mathrm{Cl}>\mathrm{I}$. I indicates antagonism (-). Synergy level: $0.85<\mathrm{Cl}<0.9+$ (slight synergism); $0.7<\mathrm{Cl}<0.85++$ (moderate synergism); $0.3<\mathrm{Cl}<0.7+++$ (synergism); $0 . \mathrm{I}<\mathrm{Cl}<0.3++++$ (potent synergism); $\mathrm{Cl}<0 . \mathrm{I}$ ++++ (very strong synergism); \pm indicates additive effects. An equipotent dendrimer/ARV range concentration between $0.01 \mu \mathrm{M}$ and I $\mu \mathrm{M}$ was used. Data from one single experiment. Each condition was tested in triplicate.

Abbreviations: $\mathrm{Cl}$, combination index; $\mathrm{EC}_{75}, 75 \%$ effective concentration; $\mathrm{EC}_{90}, 90 \%$ effective concentration; ARV, antiretroviral; AZT, zidovudine; EFV, efavirenz; TFV, tenofovir; PBMCs, peripheral blood mononuclear cells. in PBMCs for the majority of the tested combinations of dendrimers and ARVs. These combinations were assessed against the X4-HIV-1 $1_{\mathrm{NL} 4.3}$, R5-HIV-1 ${ }_{\mathrm{NL}(\mathrm{AD} 8)}$, or primary R5-subtype C-HIV-1.

\section{Synergistic profile of dendrimers and ARV combinations in TZM-bl cell line}

To confirm the results obtained in PBMCs, the combinations of G3-S16 and G2-NF16 with AZT, EFV, and TFV were also evaluated in the in vitro model of TZM-bl reporter cells ${ }^{26}$ against X4-HIV-1 ${ }_{\mathrm{NL} 4.3}$ and R5-HIV-1 ${ }_{\mathrm{NL}(\mathrm{AD} 8)}$ infection (Figure 2). All of the combinations tested resulted in a more efficient inhibitory profile against both the $\mathrm{X} 4-\mathrm{HIV}-1_{\mathrm{NL} 4.3}$ and R5-HIV-1 ${ }_{\mathrm{NL}(\mathrm{AD} 8)}$ infections compared to the effects of the individual drugs. A nearly complete or total inhibition of HIV-1 infection was reached with all of the combinations.

The CI values were calculated to evaluate the type of dendrimer and ARV interactions (Figure 3). For this purpose, fixed concentrations of $0.01 \mu \mathrm{M}$ AZT, $0.1 \mu \mathrm{M}$ EFV, and $0.01 \mu \mathrm{M}$ or $0.05 \mu \mathrm{M}$ TFV were tested in combination with increasing concentrations of G3-S16 or G2-NF16. The obtained CI values demonstrated the positive interactions between the dendrimers and ARVs, and synergy was observed for the majority of the G3-S16 + AZT, G3-S16 + TFV, G2-NF16 + AZT, and G2-NF16 + TFV combinations against both X4-HIV-1 $1_{\mathrm{NL} 4.3}$ and R5-HIV-1 $1_{\mathrm{NL}(\mathrm{AD} 8)}$ isolates (Figure 3A, B, E, and F). All of the CI values showed strong synergism or synergism, except for $1 \mu \mathrm{M} \mathrm{G} 2-\mathrm{NF} 16+$ $0.01 \mu \mathrm{M}$ AZT, which demonstrated only a slight synergism value $(\mathrm{CI}=0.808$; Figure $3 \mathrm{~B})$. Nonsynergistic or additive effects were observed when $0.01 \mu \mathrm{M}$ EFV was mixed with $0.5 \mu \mathrm{M} \mathrm{G} 3-\mathrm{S} 16$ or with concentrations of G2-NF16 higher than $0.5 \mu \mathrm{M}(\mathrm{CI}>1.1)$ against X4-HIV-1 (Figure 3C and D). Nevertheless, very strong or strong synergistic interactions were observed when higher concentration of EFV was used against both HIV-1 strains (Figure 3C and D). In summary, enhanced inhibitory effects and generally synergistic profiles were observed against both the R5 and X4-HIV-1 when the dendrimers were combined with the ARV treatments in the TZM-bl cell line, supporting the previous data obtained in the primary PBMCs.

\section{Discussion}

Currently, the development of vaginal- and rectal-administered microbicides has become one of the major focuses of the HIV-1 field to prevent the viral spread of HIV-1 during sexual intercourse. The successful CAPRISA 004 trial, which 


\section{G3-S16}

A

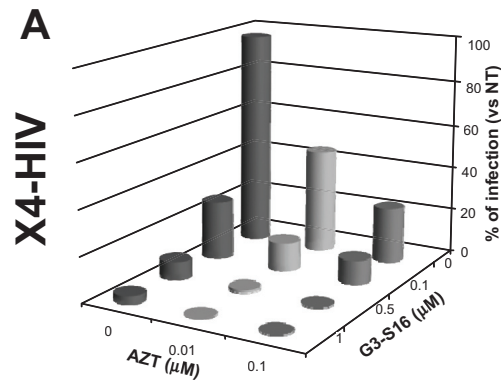

B
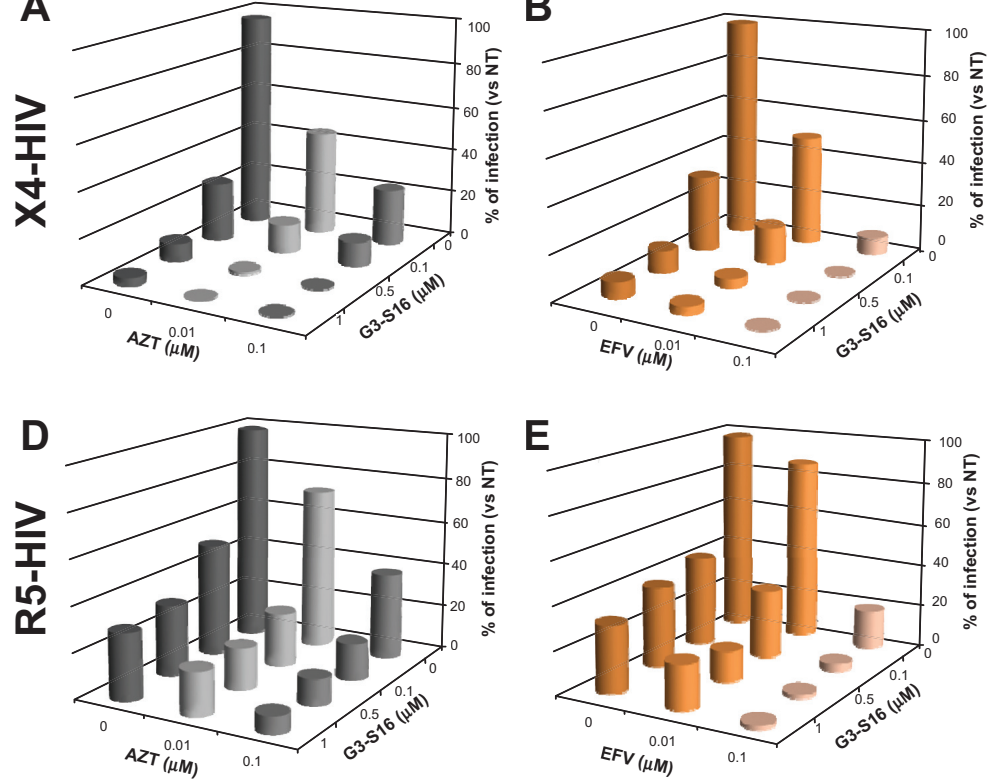

E

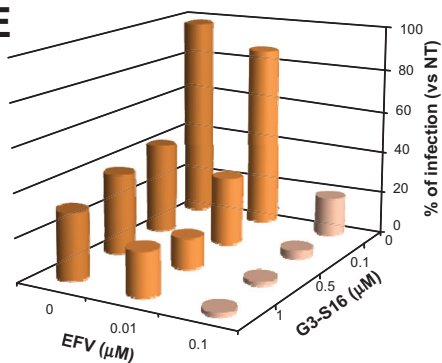

G2-NF16
C
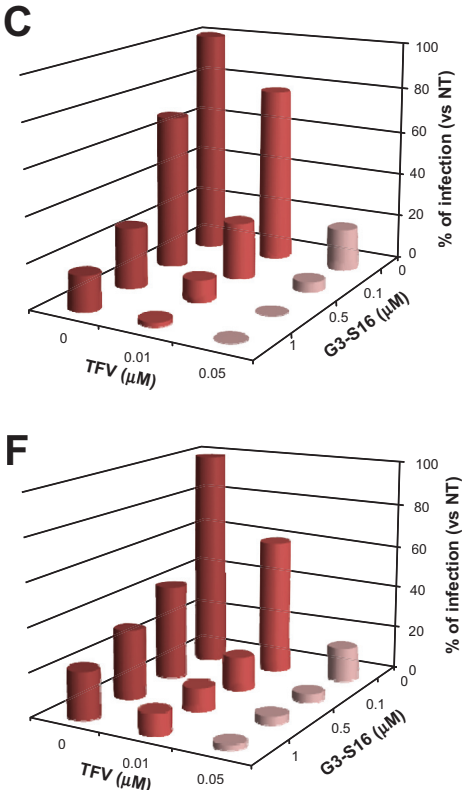
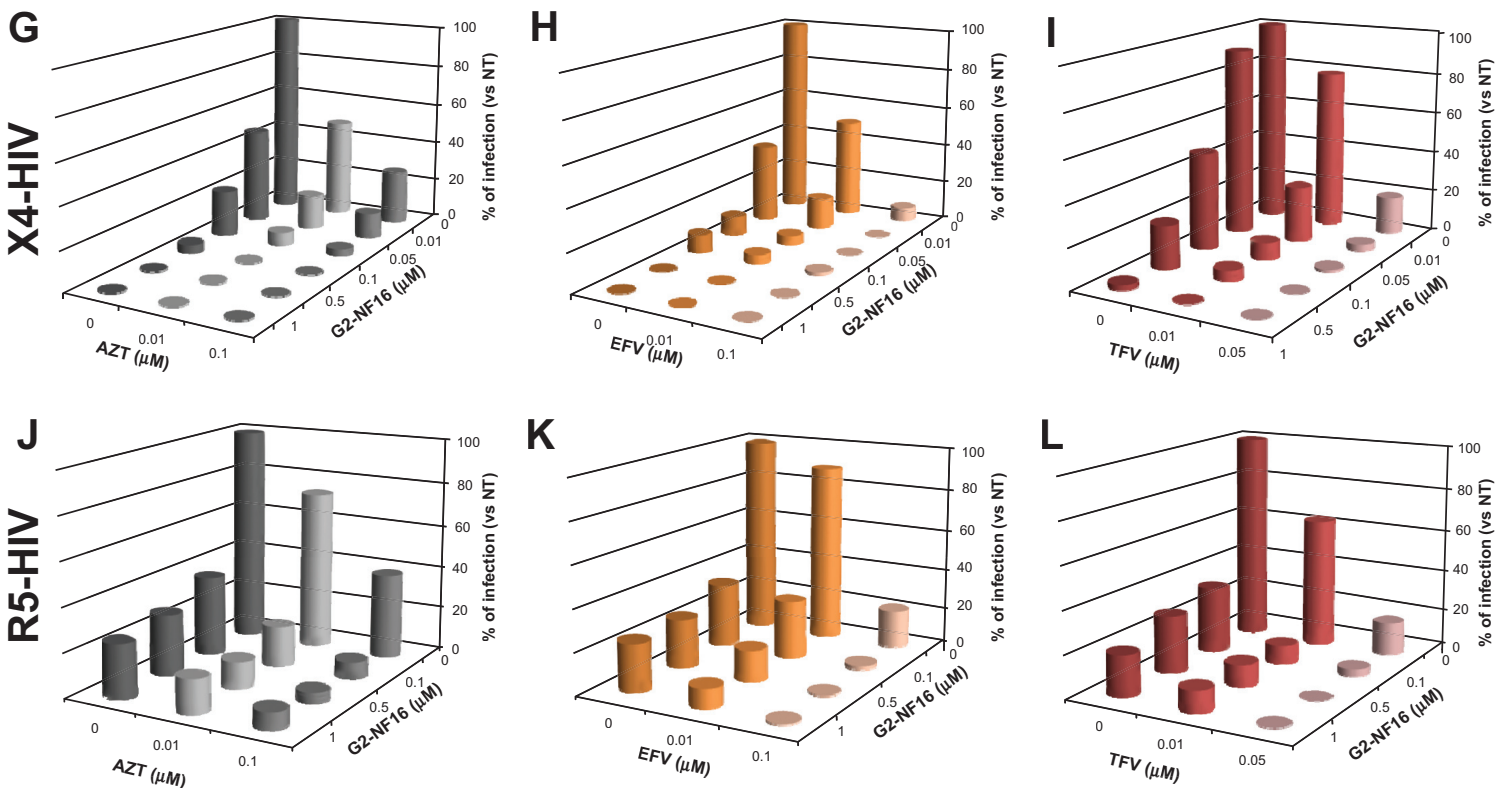

Figure 2 Activity profile of G3-SI6 (A-F) or G2-NFI6 (G-L) alone or combined with AZT (A, D, G and J), EFV (B, E, H and K) or TFV (C, F, I and L) against X4-HIV-I ${ }_{\text {NL4.3 }}\left(\mathbf{A}, \mathbf{B}, \mathbf{C}, \mathbf{G}, \mathbf{H}\right.$ and I) or R5-HIV-I ${ }_{\text {NL(AD) })}(\mathbf{D}, \mathbf{E}, \mathbf{F}, \mathbf{J}, \mathbf{K}$ and $\mathbf{L}$ ) replication (\% of infection was calculated as \% of luciferase activity vs non-treated cells) in TZMbl cell line. TZM-bl cells were treated with different combinations of G3-SI6 or G2-NFI6 carbosilane dendrimers and ARV drugs I hour before HIV-I infection. After 3 days, viral infection was quantified measuring luciferase expression levels. Each experiment was performed in triplicate. Data are represented as mean of three independent experiments.

Abbreviations: AZT, zidovudine; EFV, efavirenz; TFV, tenofovir; ARV, antiretrovirals; HIV, human immunodeficiency virus; NT, non-treated condition.

examined the use of a $1 \%$ TFV vaginal gel for the prevention of HIV-1 infection in women, opened novel perspectives in this area. ${ }^{15}$

However, the use of single drugs as microbicidal components has not been efficacious enough. Therefore, the use of combinatorial approaches with existing inhibitory drugs has become an important complement to the continued development of new therapeutic agents. For example, effective combinations of two or more drugs have been successfully used to treat several diseases, such as cancer or infectious diseases. ${ }^{31}$ Therefore, the combination of at least two different ARVs with potent anti-HIV-1 activity could be an optimized 
A

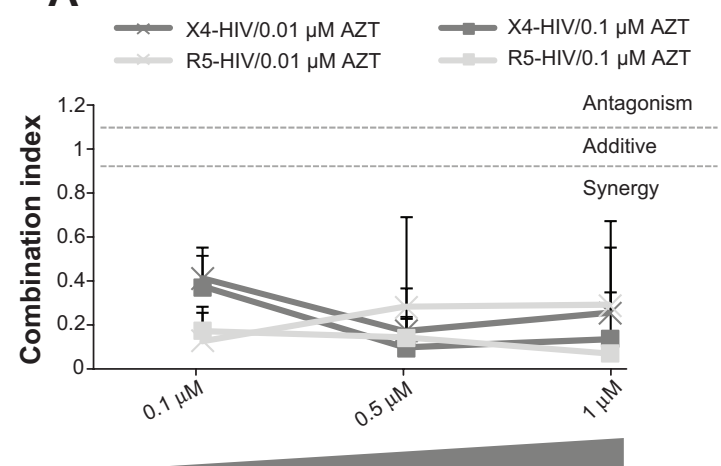

[G3-S16]

\section{C}

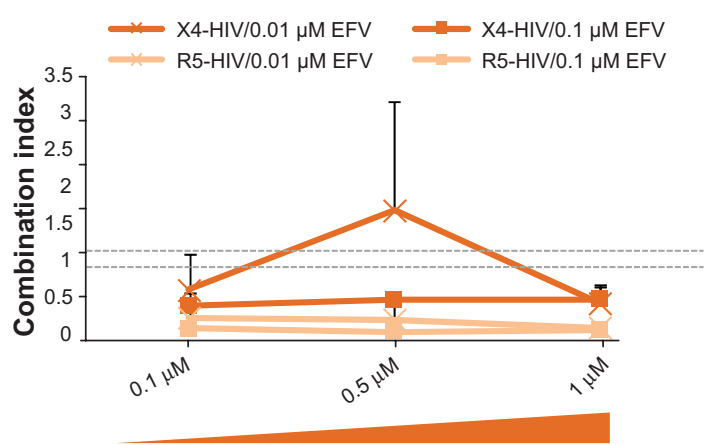

[G3-S16]

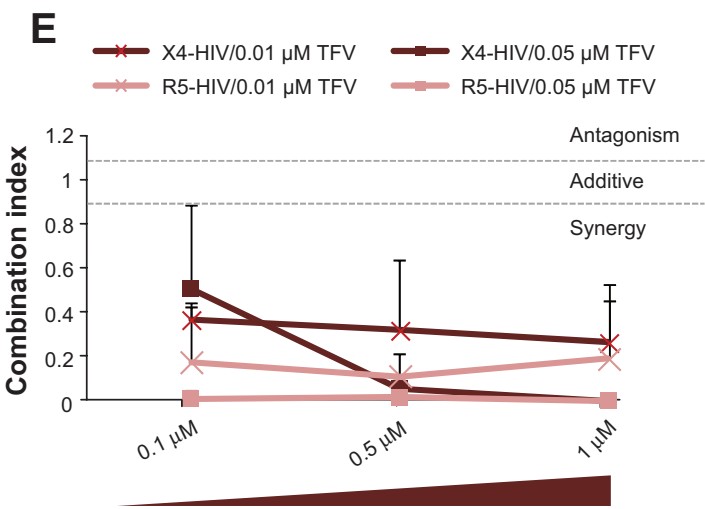

[G3-S16]

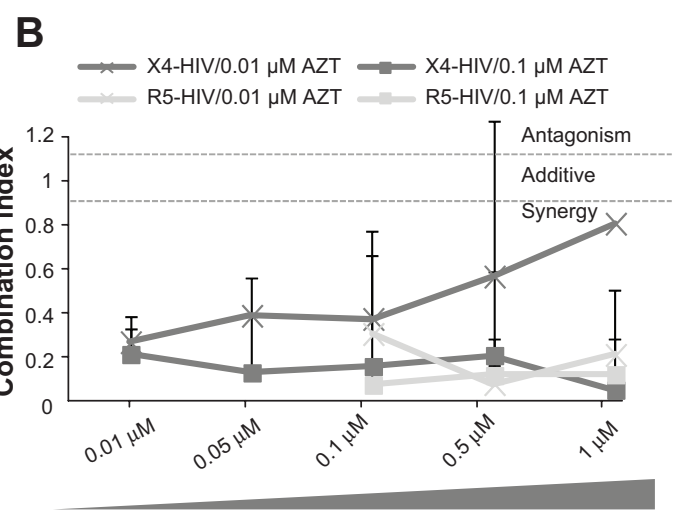

[G2-NF16]

D

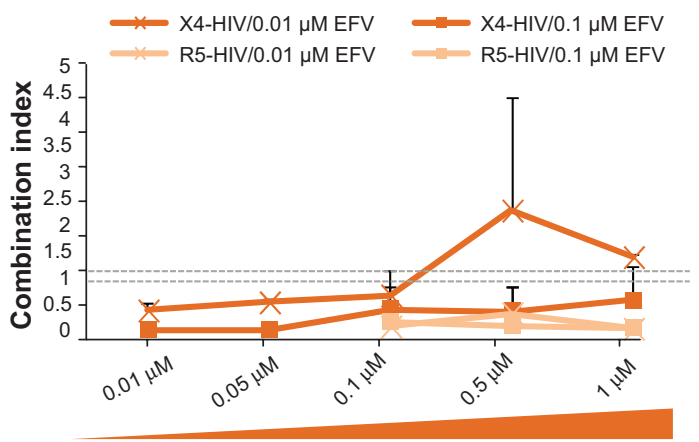

[G2-NF16]

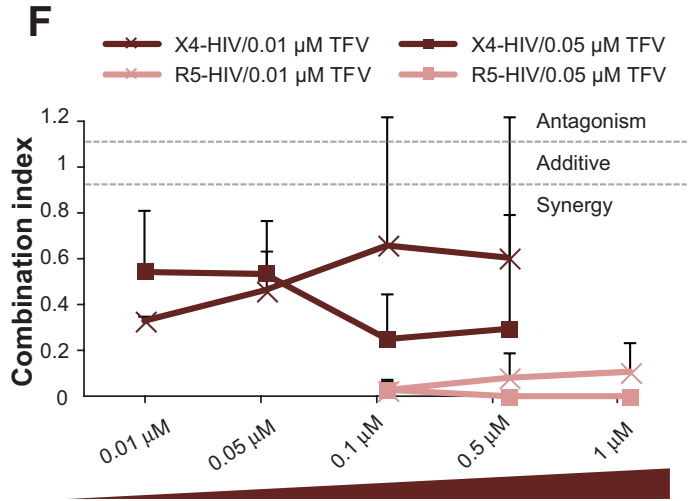

[G2-NF16]

Figure 3 Cl determination for various G3-SI6 (A, C, E) and G2-NFI6 (B, D, F) combinations with a fixed concentration of AZT, EFV or TFV against X4-HIV-I ${ }_{\text {NL4.3 }}$ and R5-HIV-I ${ }_{\text {NL(AD8) }}$ in TZM-bl cells.

Notes: $\mathrm{Cl}<0.9$ indicates synergism; $0.9<\mathrm{Cl}<\mathrm{I}$.I indicates additive effects and $\mathrm{Cl}>\mathrm{I}$.l indicates antagonism (-), showed on graphs by gray dashed lines. Synergy level: $0.85<\mathrm{Cl}<0.9$ (slight synergism); $0.7<\mathrm{Cl}<0.85$ (moderate synergism); $0.3<\mathrm{Cl}<0.7$ (synergism); $0.1<\mathrm{Cl}<0.3$ (potent synergism); $\mathrm{Cl}<0.1$ (very strong synergism).

Abbreviations: AZT, zidovudine; EFV, efavirenz; TFV, tenofovir; $\mathrm{Cl}$, combination index.

prevention strategy to fight against the sexual transmission of the virus.

Novel nanotech-derived compounds, such as carbosilane dendrimers, are explored as new antiviral drugs that could be used in these combinatorial strategies. In our study, the best combinatorial profiles were achieved with the G3-S16/ EFV and G2-NF16/TFV combinations against the X4 and R5-HIV-1 strains. However, further efforts should be carried out to research the most appropriate concentrations of these combinations, particularly before any further in vivo studies.

These combinations have the potential to block HIV-1 infection at different stages of the HIV-1 life cycle, prior viral integration, certainly explaining the positive interaction outcomes that were observed. It has been suggested that polyanionic carbosilane dendrimers could act preferentially as entry inhibitors. Their mechanisms of action have been associated with the establishment of electrostatic interactions 
between them and viral envelope proteins, such as HIV gp120, that ultimately block gp120/CD4 interaction avoiding viral entry and the subsequent infection of the target cell ${ }^{21}$ whereas, ARVs, such as AZT, EFV, and TFV play a decisive role in reverse transcriptase inhibition. Nevertheless, further studies are needed to understand the mechanisms that underlie the additive effect of the two drugs, as well as their synergistic action against HIV-1.

Targeting multiple steps within the HIV-1 replication cycle is important to reduce the risk of transmission of resistant viral strains, as well as to reduce the development of new ones. ${ }^{18}$ Additionally, a reduction in the amounts of ARVs used in vivo may result in a reduction of adverse effects, limiting the local injuries, the toxicity, and the inflammation caused by local microbicide application before sexual intercourse.

Although sexual transmission of HIV-1 mainly occurs by viruses using CCR $5,{ }^{32}$ the CXCR4 variants are also present in semen, ${ }^{33}$ and studies using macaques have shown that the $\mathrm{X} 4$ viruses can also be transmitted vaginally. ${ }^{34}$ We have demonstrated that the combination of carbosilane dendrimers with ARVs was highly effective at inhibiting R5-HIV- $1_{\text {NL(AD8) }}$ replication in our in vitro model. Moreover, two-drug combinations were also highly potent against X4-HIV- $1_{\mathrm{NL} 4.3}$ infection. Thus, the combination of carbosilane dendrimers with ARVs demonstrated a strong inhibitory effect against both viral types, as well as against the primary subtype C (R5) HIV-1 isolate, suggesting their potential activity at blocking R5 and X4 HIV-1 transmission during sexual intercourse.

In conclusion, our data demonstrated that the combination of anionic dendrimers with reverse transcriptase inhibitors, such as AZT, EFV, and TFV, increased the antiviral potency of each individual compound. This outcome is highly encouraging and supports further clinical research with these nanoparticles-based combinations as potential microbicides to fight against the worldwide spread of HIV-1.

\section{Acknowledgments}

This work was supported by grants from: Fondos de Investigación Sanitaria ISCIII (INTRASALUD PI09/02029, PI13/02016); Red Temática de Investigación Cooperativa Sanitaria ISCIII (RETIC RD06/0006/0035 and RD120017-0037, RD09-0076-00103, PT13-0010-0028); Consorcium INDISNET S-2011-BMD2332 (Comunidad de Madrid [CM]); CYTED (P213RT0409), and FIPSE to MA Muñoz-Fernández and by fellowships from CTQ2011-23245 (MEyC), Consorcium NANODENDMED
S2011/BMD-2351 (CM), CYTED and CIBER-BBN to the University of Alcalá. M Pion is supported by Spanish Ministerio de Ciencia e Innovacion (MICINN) through the Ramón y Cajal (RYC-2009-05486) and by Fondos de Investigación Sanitaria ISCIII (PI12_01763). We would like to acknowledge the Centre of Transfusion of Madrid for the buffy coats and the HIV HGM Spanish BioBank (Hospital General Universitario Gregorio Marañón, Madrid, Spain) for processing these buffy coats. The Spanish HIV HGM Biobank is supported by Red Nacional de Biobancos RD09/0076/00103.

\section{Disclosure}

The authors report no conflicts of interest in this work.

\section{References}

1. Joint United Nations Programme on HIV/AIDS. Global Report: UNAIDS report on the global AIDS epidemic 2013. Geneva: Worl Health Organization; 2013. Available from: http://www.unaids.org/ en/media/unaids/contentassets/documents/epidemiology/2013/gr2013/ UNAIDS_Global_Report_2013_en.pdf. Accessed March 18, 2014.

2. Perelson AS, Essunger P, Cao Y, et al. Decay characteristics of HIV-1-infected compartments during combination therapy. Nature. 1997;387(6629):188-191.

3. Buckheit RW Jr, Watson KM, Morrow KM, Ham AS. Development of topical microbicides to prevent the sexual transmission of HIV. Antiviral Res. 2010;85(1):142-158.

4. Abdool Karim SS, Baxter C. Microbicides and their implications in HIV prevention. Indian J Med Res. 2010;132(6):656-659.

5. Patton DL, Sweeney YT, Balkus JE, et al. Preclinical safety assessments of UC781 anti-human immunodeficiency virus topical microbicide formulations. Antimicrob Agents Chemother. 2007;51(5): 1608-1615.

6. Nel AM, Coplan P, Smythe SC, et al. Pharmacokinetic assessment of dapivirine vaginal microbicide gel in healthy, HIV-negative women. AIDS Res Hum Retroviruses. 2010;26(11):1181-1190.

7. De Clercq E. Where rilpivirine meets with tenofovir, the start of a new anti-HIV drug combination era. Biochem Pharmacol. 2012;84(3):241-248.

8. Veazey RS, Shattock RJ, Pope M, et al. Prevention of virus transmission to macaque monkeys by a vaginally applied monoclonal antibody to HIV-1 gp120. Nat Med. 2003;9(3):343-346.

9. Li L, Ben Y, Yuan S, Jiang S, Xu J, Zhang X. Efficacy, stability, and biosafety of sifuvirtide gel as a microbicide candidate against HIV-1. PLoS One. 2012;7(5):e37381.

10. Veazey RS, Ketas TJ, Dufour J, et al. Protection of rhesus macaques from vaginal infection by vaginally delivered maraviroc, an inhibitor of HIV-1 entry via the CCR5 co-receptor. J Infect Dis. 2010;202(5): 739-744.

11. Neff CP, Kurisu T, Ndolo T, Fox K, Akkina R. A topical microbicide gel formulation of CCR5 antagonist maraviroc prevents HIV-1 vaginal transmission in humanized RAG-hu mice. PLoS One. 2011;6(6):e20209.

12. Stefanidou M, Herrera C, Armanasco N, Shattock RJ. Saquinavir inhibits early events associated with establishment of HIV-1 infection: potential role for protease inhibitors in prevention. Antimicrob Agents Chemother. 2012;56(8):4381-4390.

13. Herrera C, Shattock RJ. Potential use of protease inhibitors as vaginal and colorectal microbicides. Curr HIV Res. 2012;10(1):42-52.

14. Shattock RJ, Rosenberg Z. Microbicides: topical prevention against HIV. Cold Spring Harb Perspect Med. 2012;2(2):a007385. 
15. Abdool Karim Q, Abdool Karim SS, Frohlich JA, et al. Effectiveness and safety of tenofovir gel, an antiretroviral microbicide, for the prevention of HIV infection in women. Science. 2010;329(5996):1168-1174.

16. Pirrone V, Wigdahl B, Krebs FC. The rise and fall of polyanionic inhibitors of the human immunodeficiency virus type 1. Antiviral Res. 2011;90(3):168-182.

17. Vanpouille C, Arakelyan A, Margolis L. Microbicides: still a long road to success. Trends Microbiol. 2012;20(8):369-375.

18. Pirrone V, Thakkar N, Jacobson JM, Wigdahl B, Krebs FC. Combinatorial approaches to the prevention and treatment of HIV-1 infection. Antimicrob Agents Chemother. 2011;55(5):1831-1842.

19. Ham AS, Ugaonkar SR, Shi L, et al. Development of a combination microbicide gel formulation containing IQP-0528 and tenofovir for the prevention of HIV infection. J Pharm Sci. 2012;101(4):1423-1435.

20. Sepúlveda-Crespo D, Lorente R, Leal M, et al. Synergistic activity profile of carbosilane dendrimer G2-STE16 in combination with other dendrimers and antiretrovirals as topical anti-HIV-1 microbicide. Nanomedicine. 2014;10(3):609-618.

21. Chonco L, Pion M, Vacas E, et al. Carbosilane dendrimer nanotechnology outlines of the broad HIV blocker profile. J Control Release. 2012; 161(3):949-958.

22. Jiménez JL, Pion M, de la Mata FJ, et al. Dendrimers as topical microbicides with activity against HIV. New J Chem. 2012;36:299-309.

23. Telwatte S, Moore K, Johnson A, et al. Virucidal activity of the dendrimer microbicide SPL7013 against HIV-1. Antiviral Res. 2011;90(3): 195-199.

24. Vacas Córdoba E, Arnaiz E, Relloso M, et al. Development of sulphated and naphthylsulfonated carbosilane dendrimers as topical microbicides to prevent HIV-1 sexual transmission. AIDS. 2013;27(8):1219-1229.

25. Córdoba EV, Arnáiz E, De La Mata FJ, et al. Synergistic activity of carbosilane dendrimers in combination with maraviroc against HIV in vitro. AIDS. 2013;27(13):2053-2058.
26. Platt EJ, Wehrly K, Kuhmann SE, Chesebro B, Kabat D. Effects of CCR5 and CD4 cell surface concentrations on infections by macrophagetropic isolates of human immunodeficiency virus type 1 . J Virol. 1998;72(4):2855-2864.

27. García-Merino I, de Las Cuevas N, Jiménez JL, et al; Spanish HIV BioBank. The Spanish HIV BioBank: a model of cooperative HIV research. Retrovirology. 2009;6:27.

28. Arnáiz E, Vacas-Córdoba E, Galán M, et al. Synthesis of anionic carbosilane dendrimers via "click chemistry" and their antiviral properties against HIV. Journal of Polymer Science Part A: Polymer Chemistry. 2014;52(8):1099-1112.

29. Vermeire K, Princen K, Hatse S, et al. CADA, a novel CD4-targeted $\mathrm{HIV}$ inhibitor, is synergistic with various anti-HIV drugs in vitro. AIDS. 2004;18(16):2115-2125.

30. Chou TC, Talalay P. Quantitative analysis of dose-effect relationships: the combined effects of multiple drugs or enzyme inhibitors. $A d v$ Enzyme Regul. 1984;22:27-55.

31. Barouch DH, Klasse PJ, Dufour J, Veazey RS, Moore JP. Macaque studies of vaccine and microbicide combinations for preventing HIV-1 sexual transmission. Proc Natl Acad Sci U S A. 2012;109(22):8694-8698.

32. Saba E, Grivel JC, Vanpouille C, et al. HIV-1 sexual transmission: early events of HIV-1 infection of human cervico-vaginal tissue in an optimized ex vivo model. Mucosal Immunol. 2010;3(3):280-290.

33. Grivel JC, Shattock RJ, Margolis LB. Selective transmission of R5 HIV-1 variants: where is the gatekeeper? J Transl Med. 2011; 9 Suppl 1:S6.

34. Miller CJ, Hu J. T cell-tropic simian immunodeficiency virus (SIV) and simian-human immunodeficiency viruses are readily transmitted by vaginal inoculation of rhesus macaques, and Langerhans' cells of the female genital tract are infected with SIV. J Infect Dis. 1999;179 Suppl 3: S413-S417.
International Journal of Nanomedicine

\section{Publish your work in this journal}

The International Journal of Nanomedicine is an international, peerreviewed journal focusing on the application of nanotechnology in diagnostics, therapeutics, and drug delivery systems throughout the biomedical field. This journal is indexed on PubMed Central, MedLine, CAS, SciSearch $\AA$, Current Contents ${ }^{\circledR} /$ Clinical Medicine,

\section{Dovepress}

Journal Citation Reports/Science Edition, EMBase, Scopus and the Elsevier Bibliographic databases. The manuscript management system is completely online and includes a very quick and fair peer-review system, which is all easy to use. Visit http://www.dovepress.com/ testimonials.php to read real quotes from published authors. 